\title{
Evaluation of Cytokine Messenger RNA Expression in Peripheral Blood Mononuclear Cells from Dogs with Canine Demodicosis
}

\author{
Kenji TANI ${ }^{1}$, Masahiro MORIMOTO ${ }^{2)}$, Toshiharu HAYASHI'), Hisashi INOKUMA ${ }^{3)}$, Takafumi OHNISHI ${ }^{3)}$, \\ Sanae HAYASHIYA ${ }^{1)}$, Tadayoshi NOMURA ${ }^{4)}$, Satoshi UNE $^{1)}$, Munekazu NAKAICHI ${ }^{1)}$ and Yasuho TAURA ${ }^{1) *}$ \\ ${ }^{1)}$ Departments of Veterinary Surgery, ${ }^{2)}$ Veterinary Pathology, ${ }^{3)}$ Veterinary Internal Medicine and ${ }^{4)}$ Veterinary Hospital, Faculty of \\ Agriculture, Yamaguchi University, 1677-1 Yoshida, Yamaguchi 753-8515, Japan
}

(Received 15 August 2001/Accepted 27 February 2002)

ABSTRACT. Using RT-PCR and semi-quantitative PCR, mRNA expression for canine interferon (IFN)- $\gamma$, interleukin (IL)-2, IL-4, IL-5, IL10 , tumor necrosis factor (TNF)- $\alpha$ and transforming growth factor (TGF)- $\beta$ in peripheral blood mononuclear cells (PBMCs) was examined in dogs with or without demodicosis. mRNA expression for IFN- $\gamma$ as well as TNF- $\alpha$ in dogs with demodicosis (localized (LD) and generalized (GD)) was slightly lower than those in dogs without demodicosis (healthy controls). Expression of IL-5 mRNA in dogs with demodicosis was higher than that in control dogs, but there were no significant differences in IL-4 and IL-10 mRNA expression levels among the three groups. On the other hand, expression levels of TGF- $\beta$ mRNA in dogs with GD were higher than those in control dogs and dogs with LD. The expression levels of IL-5 and TGF- $\beta$ mRNA decreased in all three dogs with GD which showed resolution of the clinical signs. Taken together, these results suggest that the Th2-like response in PBMCs from dogs with demodicosis is up-regulated, and that subsequent increased expression of IL- 5 and TGF- $\beta$ mRNA in dogs with GD is reversible after treatment. Therefore, these cytokines, particularly IL-5, might be a useful clinical index of the clinical course in demodicosis. Also, increased TGF- $\beta$ mRNA expression might be a key factor for revealing the difference in the mechanism of onset between LD and GD.

KEY WORDS: canine, cytokine, demodicosis, mRNA, RT-PCR.

J. Vet. Med. Sci. 64(6): 513-518, 2002

Canine demodicosis is an inflammatory parasitic skin disease characterized by excessive proliferation of Demodex canis within the hair follicles [28] and/or Demodex spp. on the skin surface [8]. It has been thought that immunodeficiency may contribute to the development of demodicosis $[3,20,28]$. Canine demodicosis is classified as either localized (LD) or generalized (GD) depending on the extent of the skin lesions, and their immunological responses differ $[3,28]$. The decrease in the mitogen-stimulated response of peripheral blood mononuclear cells (PBMC) is more severe in GD than in LD [3, 25]. Caswell et al. [5] reported that the cell-mediated immune response may suppress the development of GD. Day [11] reported a possible decrease of T cell-derived cytokines in dogs with GD. Cytokines play an important role in development of the immune response and its regulation [4], and thus cytokine profiles contribute to the effect of immunity level in the disease. However, only a decrease of interleukin (IL)-2 and IL-2 receptor expression has been reported in canine demodicosis [21].

$\mathrm{T}$ helper 1 (Th1) cells produce IL-2 and interferon (IFN)- $\gamma[7,9]$, whereas T helper 2 (Th2) cells produce IL-4, IL-5 and IL-10 $[9,30]$. Th1 and Th2 cells are regulated by a mutual inhibition system [24]. These cells expand in secondary lymphoid tissues such as lymph nodes. However, as sampling from lymph nodes is risky and difficult for temporal studies, this approach is impractical. It has been reported that cytokine profiles in PBMC reflect those in the lymph

\footnotetext{
* Correspondence to: Taura, Y., Department of Veterinary Surgery, Faculty of Agriculture, Yamaguchi University, 1677-1 Yoshida, Yamaguchi 753-8515, Japan.
}

node $[15,22]$. An imbalance between Th1 and Th2 responses in PBMC has been suggested in human diseases $[1,30,31]$. These data from PBMC may be useful in small animal veterinary practice, particularly as a clinical parameter for monitoring the clinical course of canine demodicosis. Apart from Th-type cytokines, tumor necrosis factor (TNF)- $\alpha$ plays an important role in the inflammatory process [32]. Transforming growth factor (TGF)- $\beta$ is an antiinflammatory cytokine designated as Th3 [6], which suppresses the growth of Th1 and Th2 and also B cells [13]. The purpose of this study was to determine whether or not cytokine mRNA expression is directly detectable in PBMC ex vivo and to evaluate the cytokine profiles of dogs with canine demodicosis. It was anticipated that the results might provide further understanding of the immune status in canine demodicosis.

\section{MATERIALS AND METHODS}

Animals: Twenty-nine dogs were used in this study. They were grouped: 10 healthy dogs, 9 dogs with LD, and 10 dogs with GD (Table 1). The clinical diagnosis of demodicosis was confirmed by the findings of increased numbers of mites in skin scrapings. Canine GD was defined as demodicosis involving at least $50 \%$ of the body. In this study, dogs less than 1 year old at the on-set of clinical signs were considered to have juvenile on-set demodicosis. Dogs more than 1 year old at the on-set of clinical signs were considered to have adult on-set demodicosis. The cytokine mRNA expression in three dogs (No. 22, 24, and 27) with GD was examined when they had complete resolution of clinical 
Table 1. Clinical details of dogs

\begin{tabular}{|c|c|c|c|c|c|c|}
\hline Group & Dog no. & Breed & Sex & Age & Age of on-set & Other disease \\
\hline \multirow{10}{*}{ Healthy } & 1 & Beagle & M & $4.5 \mathrm{y}$ & - & Undefined \\
\hline & 2 & Beagle & M & $4 y$ & - & Undefined \\
\hline & 3 & Beagle & M & $4.5 \mathrm{y}$ & - & Undefined \\
\hline & 4 & Beagle & $\mathrm{M}$ & $7 \mathrm{~m}$ & - & Undefined \\
\hline & 5 & beagle & $\mathrm{M}$ & $3.5 y$ & - & Undefined \\
\hline & 6 & Beagle & $\mathrm{M}$ & $7 \mathrm{~m}$ & - & Undefined \\
\hline & 7 & Beagle & $\mathrm{F}$ & $7 \mathrm{~m}$ & - & Undefined \\
\hline & 8 & Beagle & $\mathrm{M}$ & $3.5 \mathrm{y}$ & - & Undefined \\
\hline & 9 & Beagle & $\mathrm{F}$ & $3.0 \mathrm{y}$ & - & Undefined \\
\hline & 10 & Beagle & $\mathrm{F}$ & $4.5 \mathrm{y}$ & - & Undefined \\
\hline \multirow{9}{*}{ LD } & 11 & Beagle & $\mathrm{F}$ & $14 \mathrm{~m}$ & $7 \mathrm{~m}$ (juvenile) & Undefined \\
\hline & 12 & Pomeranian & $\mathrm{M}$ & $12 \mathrm{y}$ & $12 \mathrm{y}$ (adult) & Undefined \\
\hline & 13 & Maltese & $\mathrm{M}$ & $16 y$ & 16y (adult) & Hyperadenocorticism \\
\hline & 14 & Pembroke Welsh corgi & $\mathrm{F}$ & $5 \mathrm{~m}$ & $5 \mathrm{~m}$ (juvenile) & Undefined \\
\hline & 15 & Pembroke Welsh corgi & M & $21 \mathrm{~m}$ & $5 \mathrm{~m}$ (juvenile) & Undefined \\
\hline & 16 & French bulldog & M & $6 \mathrm{~m}$ & $6 \mathrm{~m}$ (juvenile) & Undefined \\
\hline & 17 & Scottish terrier & $\mathrm{M}$ & $13 y$ & 10y (adult) & Pyoderma \\
\hline & 18 & Shiba-inu & $\mathrm{F}$ & $7 y$ & $7 y$ (adult) & Undefined \\
\hline & 19 & Shiba-inu & $\mathrm{F}$ & $16 \mathrm{~m}$ & $15 \mathrm{~m}$ (adult) & Undefined \\
\hline \multirow{10}{*}{ GD } & 20 & Shih Tzu & M & $8 y$ & 7.8y (adult) & Pyoderma \\
\hline & 21 & Shih Tzu & M & $3.5 \mathrm{y}$ & 3y (adult) & Undefined \\
\hline & 22 & Shih Tzu & $\mathrm{MN}$ & $13 y$ & 4y (adult) & Pyoderma \\
\hline & 23 & Siberian husky & M & $11 \mathrm{y}$ & 11y (adult) & Chronic renal failure \\
\hline & 24 & Dalmatian & $\mathrm{F}$ & $7 \mathrm{~m}$ & 6m (juvenile) & Undefined \\
\hline & 25 & Golden retriever & $\mathrm{F}$ & $6 \mathrm{~m}$ & $5 \mathrm{~m}$ (juvenile) & Undefined \\
\hline & 26 & Pembroke Welsh corgi & $\mathrm{F}$ & $4.5 \mathrm{~m}$ & $2 \mathrm{~m}$ (juvenile) & Undefined \\
\hline & 27 & Mongrel & $\mathrm{M}$ & $4 \mathrm{~m}$ & $2 \mathrm{~m}$ (juvenile) & Hypereosinophilia, Pyoderma \\
\hline & 28 & Mongrel & $\mathrm{F}$ & $6 \mathrm{~m}$ & $5 \mathrm{~m}$ (juvenile) & Hypereosinophilia \\
\hline & 29 & Tosa-inu & $\mathrm{M}$ & $10 \mathrm{~m}$ & $8 \mathrm{~m}$ (juvenile) & Pyoderma \\
\hline
\end{tabular}

Healthy, healthy control dogs; LD, localized demodicosis; GD, generalized demodicosis; M, male; MN, neutered male; F, female; y, years; $\mathrm{m}$, months.

signs under ivermectin treatment [32].

Cell preparation: Peripheral blood mononuclear cells (PBMC) were isolated using Ficoll-Hypaque (Pharmacia, Uppsala, Sweden) density gradient centrifugation. The cells were treated for 10 min with $17 \mathrm{mM}$ Tris-HCL, containing $0.75 \%$ ammonium chloride ( $\mathrm{pH} 7.2$ ) to lyse any contaminating erythrocytes, and then were washed twice with phosphate-buffered saline ( $\mathrm{pH}$ 7.4). The PBMC were adjusted to $0.5 \times 10^{6}$ cells and then lysed under highly denaturing conditions by use of a lysis buffer included in a commercial kit (QIAamp RNA Blood Mini Kit, Qiagen). They were then preserved at $-80^{\circ} \mathrm{C}$ until total RNA was isolated as described below.

Total RNA extraction: Total RNA was isolated in a kit following the manufacture's protocol. Briefly, the lysed PBMC was homogenized through a QIAshredder ${ }^{\mathrm{TM}}$ spin column. Ethanol was added to adjust binding conditions and the sample was applied to the QIAamp spin column. RNA bound to the silica-gel membrane during a brief centrifugation step. The contaminants were washed away and total RNA was eluted in $100 \mu l$ of RNase -free water.

$R T-P C R$ : We reverse-transcribed $10 \mu l$ of elution RNA with murine reverse transcriptase following the manufacture's protocol (Ready To Go RT-PCR, Pharmacia). The suitability of the primers for PCR, and the appropriate conditions, were established using RNA isolated from stimulated canine PBMC (data not shown). The primers used for the PCR reaction are summarized in Table 2 . The sequences for canine IFN- $\gamma$, IL-4, and IL-10 cDNAs were obtained from the National Institute of Health's Genbank. Each primer set was chosen to cover at least two different exons, so that we could differentiate easily between amplified mRNA and possible contaminating genomic DNA. The sequences for the other cytokines have already been published. We elected to amplify the mRNA encoding the housekeeping protein glyceraldehyde-3-phosphate dehydrogenase (GAPDH). We performed PCR using the appropriate cycles $\left(1 \mathrm{~min}\right.$ at $94^{\circ} \mathrm{C}, 1 \mathrm{~min}$ at $59.5^{\circ} \mathrm{C}$ for TNF- $\alpha$ and TGF- $\beta$, or $1 \mathrm{~min}$ at $94^{\circ} \mathrm{C}$ then $1 \mathrm{~min}$ at $57^{\circ} \mathrm{C}$, followed by $1.5 \mathrm{~min}$ at $72^{\circ} \mathrm{C}$ for the other cytokines) within the linear amplification ranges as follows: 30 cycles for GAPDH, 40 cycles for TNF- $\alpha$ and TGF- $\beta$, and 45 cycles for the other cytokines. Samples from PCR reactions were separated by electrophoresis through a $2.5 \% \mathrm{TAE}$ agarose gel. The gel was stained with ethidiun bromide, and DNA was quantified by densitometry (AE-6920WSE, ATTO, Japan). Relative levels of cytokine expression were compared with normalized GAPDH transcripts and presented as the ratio of band 
Table 2. Sequence of primers for amplification of canine cytokine-gene transcripts

\begin{tabular}{|c|c|c|c|c|}
\hline & Primer set & & Product & Reference \\
\hline \multirow[t]{2}{*}{ IFN- $\gamma$} & Sense & 5'-CCAGATGTATCGGACGGTGG-3' & $360 \mathrm{bp}$ & L24956* \\
\hline & Anti-sense & 5'-TTATCGCCTTGCGCTGGACC-3' & & \\
\hline \multirow[t]{2}{*}{ IL-2 } & Sense & 5'-GTGCGCCTATTACTTCAAGCTC-3' & $345 \mathrm{bp}$ & [24] \\
\hline & Anti-sense & 5'-GCTGTCTCGTCATCATATTC-3' & & \\
\hline \multirow[t]{2}{*}{ IL-4 } & Sense & 5'-ATGGGTCTCACCTCCCAACTG-3' & 399 bp & AF187322 \\
\hline & Anti-sense & 5’-TCAATGCCTGTAGTATTTCTTC-3' & & \\
\hline \multirow[t]{2}{*}{ IL-5 } & Sense & 5'-GGTGAAAGAGACCTTGGCAC-3' & $305 \mathrm{bp}$ & {$[24]$} \\
\hline & Anti-sense & 5'-CACTCGGTGTTCATTACACC-3' & & \\
\hline \multirow[t]{2}{*}{ IL-10 } & Sense & 5'-TACCTGGGTTGCCAAGCCCT-3' & $517 \mathrm{bp}$ & U33843 \\
\hline & Anti-sense & 5'-TTCACAGAGAAGCTCAGTAAAT-3' & & \\
\hline \multirow[t]{2}{*}{ TNF- $\alpha$} & Sense & 5'-CCAAGTGACAAGCCAGTAGC-3' & $274 \mathrm{bp}$ & {$[14]$} \\
\hline & Anti-sense & 5'-TCTTGATGGCAGAGAGTAGG-3' & & \\
\hline \multirow[t]{2}{*}{ TGF- $\beta$} & Sense & 5'-TTCCTGCTCCTCATGGCCAC-3' & $393 \mathrm{bp}$ & {$[14]$} \\
\hline & Anti-sense & 5'-GCAGGAGCGCACGATCATGT-3' & & \\
\hline \multirow[t]{2}{*}{ GAPDH } & Sense & 5'-GCCAAAAGGGTCATCATCTC-3' & 229 bp & [15] \\
\hline & Anti-sense & 5'-GGCCATCCACAGTCTTCT-3' & & \\
\hline
\end{tabular}

* GenBank accession number.

Table 3. Average ratio of the cytokine/GAPDH mRNA expression and significance levels of their differences

\begin{tabular}{lccccccc}
\hline & IFN- $\gamma$ & IL-2 & IL-4 & IL-5 & IL-10 & TNF- $\alpha$ & TGF- $\beta$ \\
\hline 1. Healthy (n=10) & $0.19 \pm 0.18^{*}$ & $0.89 \pm 0.24$ & $0.07 \pm 0.10$ & $0.20 \pm 0.18$ & $0.35 \pm 0.06$ & $1.25 \pm 0.22$ & $1.21 \pm 0.28$ \\
2. LD (n=9) & $0.07 \pm 0.10$ & $1.14 \pm 0.15$ & $0.02 \pm 0.07$ & $0.42 \pm 0.19$ & $0.22 \pm 0.19$ & $0.55 \pm 0.39$ & $1.33 \pm 0.22$ \\
3. GD (n=10) & $0.09 \pm 0.13$ & $0.90 \pm 0.21$ & $0.08 \pm 0.21$ & $0.47 \pm 0.31$ & $0.27 \pm 0.22$ & $0.63 \pm 0.37$ & $1.72 \pm 0.31$ \\
\hline Significance (P) & & & & & & & \\
1 vs. 2 & $<0.05$ & $<0.05$ & NS & $<0.05$ & NS & $<0.01$ & NS \\
1. vs. 3 & NS & NS & NS & $<0.05$ & NS & $<0.01$ & $<0.01$ \\
2 vs. 3 & NS & $<0.05$ & NS & NS & NS & NS & $<0.01$ \\
\hline
\end{tabular}

* Mean \pm SD; LD, localized demodicosis; GD, generalized demodicosis; NS, not significant.

intensities of the cytokine RT-PCR amplification product over the corresponding GAPDH RT-PCR product.

Statistical analysis: Statistical analysis was performed using the Mann-Whitney $U$ test. A value of $\mathrm{P}<0.05$ was considered to be significant. Results are expressed as the mean \pm standard deviation (SD). Correlation coefficients were determined using Pearson's linear regression analysis.

\section{RESULTS}

As shown in Table 3, levels of expression of IFN- $\gamma$ and TNF- $\alpha$ mRNA in dogs with demodicosis were lower than those in control dogs, although no significant difference in IFN- $\gamma$ expression was observed in dogs with GD. In contrast, levels of IL-2 mRNA expression in dogs with LD were higher than those in control dogs $(\mathrm{P}<0.05)$ or dogs with GD $(\mathrm{P}<0.05)$.

Levels of IL-5 mRNA expression in dogs with demodicosis (LD or GD) were higher than those in control dogs $(\mathrm{P}<0.05)$, whereas there were no significant differences in IL-4 and IL-10 mRNA expression among the three groups. In particular, the level of IL-5 mRNA (0.998 and 0.810, respectively) in two dogs with eosinophilia was markedly increased. Levels of TGF- $\beta$ mRNA expression in dogs with
GD were higher than those in control dogs and dogs with LD (both $\mathrm{P}<0.01$ ). There was no significant difference in mRNA expression between adult and juvenile onset cases. We observed that there was no difference in mRNA expression between dogs with or without pyoderma accompanying their demodicosis, although we did not confirm it because of the small number of cases with pyoderma.

The duration of LD ( $7 \pm 12$ months) did not differ significantly from that of GD $(12.9 \pm 33$ months $)$. There was a mild correlation between disease duration and the expression of IFN- $\gamma$ mRNA in dogs with demodicosis (LD and GD) $(\mathrm{r}=0.46, \mathrm{P}<0.05)$. There was no statistically significant correlation between disease duration and the expression of other cytokine mRNAs.

Levels of IFN- $\gamma$ mRNA expression increased in two of three dogs with GD that showed complete resolution of the clinical signs (Fig. 1A). Levels of TNF- $\alpha$ mRNA expression in two dogs of the three were slightly decreased, whereas that of dog No. 27 increased (Fig. 1B). However, these levels of TNF- $\alpha$ mRNA were still low compared with control dogs. The level of IL-2 mRNA expression increased and that of IL-5 mRNA expression (Fig. 1C) decreased in all three dogs. TGF- $\beta$ mRNA expression decreased slightly in all three dogs (Fig. 1D), although the levels in two of them 

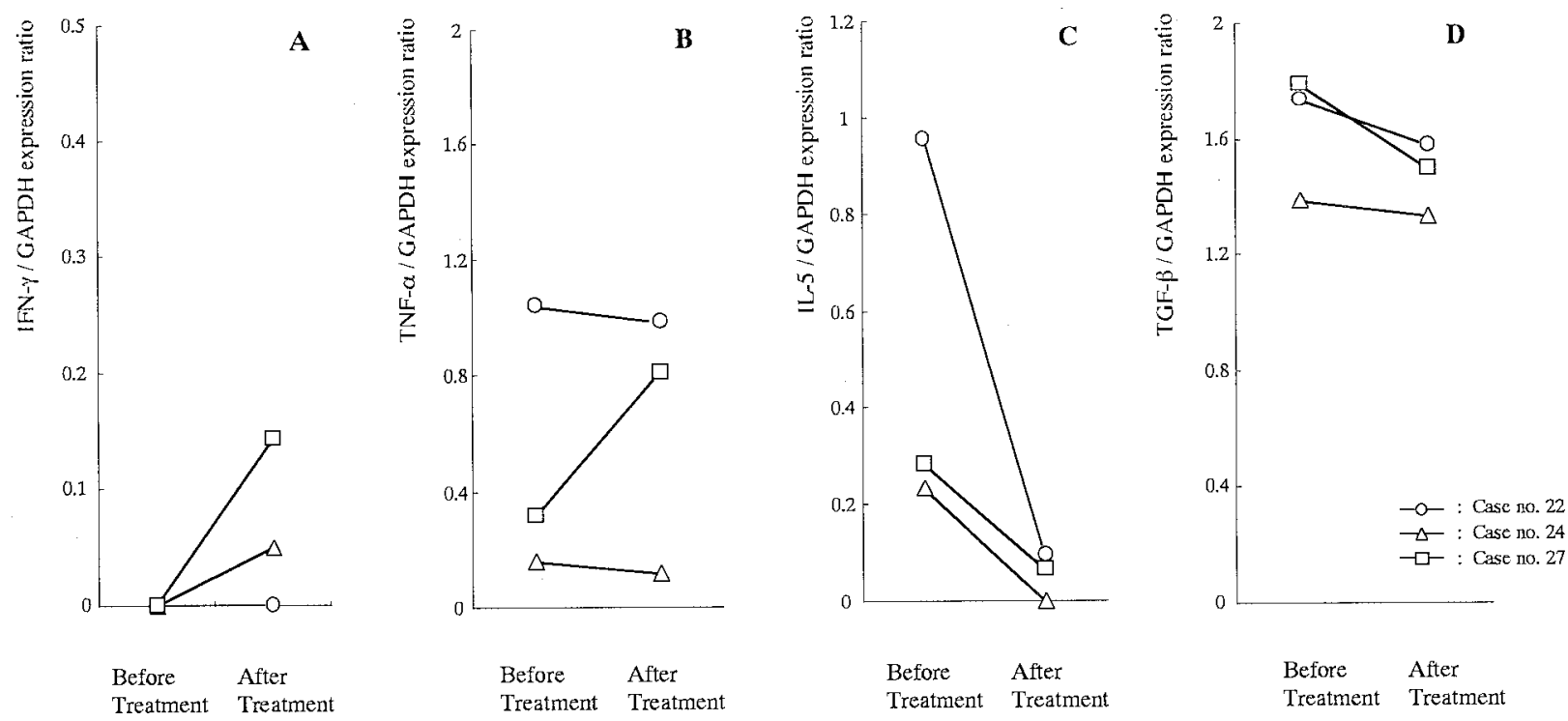

Fig. 1. Interferon- $\gamma$ (A), TNF- $\alpha$ (B), IL-5 (C) and TGF- $\beta$ (D) mRNAs expression in PBMCs from three dogs with generalized demodicosis (GD) that showed complete resolution of the clinical signs. Ratios between cytokine and GAPDH transcripts measured with AE-6920WSE (ATTO, Japan) are shown for individuals.

were still higher than in controls.

\section{DISCUSSION}

We were able to detect mRNA encoding canine cytokines in PBMC directly ex vivo without in vitro stimulation. Therefore, the present results provide a true indication of the in vivo status of cytokine profiles in dogs with demodicosis. The levels of IL-5 mRNA expression in dogs with LD and GD were higher than those in control dogs. In three dogs with GD that showed complete resolution of the clinical signs, the levels of IL-5 mRNA expression decreased and were within the normal range. These results suggest that the increased level of IL-5 mRNA expression might have been induced by Demodex mites and that the level of IL-5 mRNA expression might be a useful clinical parameter for monitoring the clinical course of GD. In general, IL- 4 and IFN- $\gamma$ are thought to be key indices of Th1 and Th2 activity, respectively [24]. In this study, however, there was no significant difference in the levels of IL-4 mRNA expression, perhaps because of the very low detection level of IL-4 mRNA expression in our system that might have masked any real differences among the groups. Although we failed to detect any increase of IL-4 mRNA expression in dogs with demodicosis, our results suggest that IL-5 induces a Th2-like response in infected dogs because IL- 5 is produced by activated Th2 cells [9].

The levels of IFN- $\gamma$ mRNA expression in dogs with LD were lower than those in control dogs, although dogs with GD showed no significant difference in this parameter from controls or dogs with LD. Therefore, the Th1-like response seemed to be down-regulated in dogs with LD. The Th1 response of the host is driven by bacterial stimuli [12], whereas mice with disrupted IFN- $\gamma$ genes show high sensitivity to bacterial infection [10]. The duration of demodicosis was correlated with the level of IFN- $\gamma$ mRNA expression, indicating that development of demodicosis might increase the expression of IFN- $\gamma$ mRNA. However, the incidence of pyoderma was not correlated with the duration of demodicosis nor the level of IFN- $\gamma$ mRNA expression, considering that the clinical incidence of pyoderma may be an index of bacterial infection. Although the level of IFN- $\gamma$ mRNA expression may be decreased at an early stage in both LD and GD, our results showed that IFN- $\gamma$ mRNA expression in dogs with GD did not differ from that in control dogs. On the other hand, Lemarie and Horohov [21] have suggested that the Th1 response is decreased in dogs with GD due to decreased IL-2 and IL-2 receptor expression. However, IL-2-deficient mice exhibit normal T cell development and subset composition, whereas IL-2 ${ }^{-/-}$ mice display markedly reduced in vitro $\mathrm{T}$ cell responses [27]. Also, our results indicate that IL-2 mRNA expression was normal in dogs with GD and was enhanced in dogs with LD. Even at an early disease stage when the Th1 response might have been decreased, IL-2 mRNA expression did not decrease. Therefore, the Th1 response may decrease in dogs with LD, and possibly in those with GD, due to decreased production of IFN- $\gamma$ rather than the IL- 2 in vivo status. However, the precise reason for the difference is still unknown.

Tumor necrosis factor has theoretically evolved to preserve cellular and biochemical homeostasis by participating in tissue remodeling and the host defense response [33]. Our study revealed that the level of TNF- $\alpha$ mRNA expres- 
sion in dogs with LD and GD decreased. In three dogs with GD that showed complete resolution of the clinical signs, the level of TNF- $\alpha$ mRNA expression varied, thus showing that it is not a suitable clinical parameter for monitoring canine demodicosis because the response does not always reflect the clinical signs. TGF- $\beta$ mRNA expression in dogs with GD was higher than in the other two groups. The importance of TGF- $\beta$ in immunoregulation and tolerance has been increasingly recognized $[17-19,26]$. TGF- $\beta$ inhibits the effects and/or production of IFN- $\gamma$, TNF- $\alpha$, IL2 , and IL-2 receptor [13]. A high concentration of TGF- $\beta$ inhibits a variety of macrophage activities and plays an important role in infection by parasites, such as Trypanosoma cruzi [2]. The role of increased TGF- $\beta$ mRNA expression in PBMC from dogs with GD remains to be further characterized and might be complex. However, increased TGF- $\beta$ mRNA expression may be associated with the immunosuppression seen in dogs with GD $[3,20,28]$. It is also possible that TGF- $\beta$ might be secreted to protect cytotoxic immunity, such as that of $\mathrm{CD}^{+} \mathrm{T}$ cells [5]. The mechanism of LD and GD onset is still unclear; LD does not always develop to GD. TGF- $\beta$ has multiple effects [13] and thus its role in demodicosis is also unclear. However, there was a difference in the level of TGF- $\beta$ mRNA expression between LD and GD. Further analysis of TGF- $\beta$ in dogs with GD may reveal differences in the mechanism of onset between LD and GD. Nevertheless, expression of TGF- $\beta$ mRNA is not a suitable clinical parameter for monitoring canine demodicosis because it does not completely normalize after complete resolution of the clinical signs.

In conclusion, we have been able to detect differences of cytokine profiles in PBMC directly ex vivo without in vitro stimulation in dogs with LD and GD. We revealed that the Th2-like response in PBMC from dogs with demodicosis was up-regulated, and that IL-5 mRNA expression might be a useful parameter for monitoring the clinical course. Expression of TGF- $\beta$ mRNA might be a key factor for revealing differences in the mechanism of onset of demodicosis. A better understanding of cytokine profiles might lead to new treatment strategies for dogs with demodicosis.

ACKNOWLEDGEMENTS. We would like to thank Prof. H. Iwata of Department of Veterinary Hygiene, Yamaguchi University, Japan for calculating the quantity of DNA, and Prof. A. Sakamoto of Department of Surgery, Kagoshima University, Drs. K. Sasaki, T. Amimoto and N. Watanabe of a private animal hospital for referring the cases.

\section{REFERENCES}

1. Asselin-Paturel, C., Echchhakir, H., Carayol, G., Gay, F. and Opolon, P. 1998. Quantitative analysis of Th1, Th2 and TGF$\beta 1$ cytokine expression in tumor, TIL and PBL of non-small cell lung cancer patients. Int. J. Cancer. 77: 7-12.

2. Barral-Netto, M., Barral, A., Brownwell, C. E., Skeiky, Y. A., Ellingsworth, L. R., Twardzik, D. R. and Reed, S. G. 1992. Transforming growth factor- $\beta$ in leishmanial infection: a parasite escape mechanism. Science 257: 545-548.
3. Barriga, O. O., Al-Khalidi, N. W., Martin, S. and Wyman, M. 1992. Evidence of immunosuppression by Demodex canis. Vet. Immunol. Immunopathol. 32: 37-46.

4. Bloom, B. R., Salgame, P. and Diamond, B. 1992. Revisiting and revising suppressor T cells. Immunol. Today 13: 131-136.

5. Caswell, J. L., Yager, J. A., Parker, W. M. and Moore, P. F. 1997. A prospective study of the immunophenotype and temporal changes in the histologic lesions of canine demodicosis. Vet. Pathol. 34: 279-287.

6. Chen, Y., Kuchroo, V. K. and Inobe, J. 1992. Regulatory T cell clones induced by oral tolerance: Suppression of autoimmune encephalomyelitis. Science 265: 1237-1240.

7. Cher, D. J. and Mosmann, T. R. 1987. Two types of murine helper T cell clone. II. Delayed-type hypersensitivity is mediated by Th1 clones. J. Immunol. 138: 3688-3694.

8. Chesney, C. J. 1999. Short form of Demodex species mites in the dog: occurrence and measurements. J. Small. Anim. Pract. 40: $58-61$.

9. Cherwinski, K. M., Schumacher, J. H., Brown, K. D. and Mosmann, T. 1990. Two type of mouse helper T cell clone III. Further differences in lymphokine synthesis between Th1 and Th2 clones revealed by RNA hybridization, functionally monospecific bioassays, and monoclonal antibodies. J. Exp. Med. 166: 1229-1244.

10. Dalton, D. K., Pitts-Meek, S., Keshav, S., Figari, I. S., Bradley, A. and Stewart, T. A. 1993. Multiple defects of immune cell function in mice with disrupted interferon-gamma genes. Science 259: 1739-1742.

11. Day, M. J. 1997. An immunohistochemical study of the lesions of demodicosis in the dog. J. Comp. Pathol. 116: 203-216.

12. Del Prete, G. F., De Carli, M., Mastromauro, C., Biagiotti, R., Macchia, D., Falagiani, P., Ricci, M. and Romagnari, S. 1991. Purified protein derivative of Mycobacterium tuberculosis and excretory-secretory antigen(s) of Toxocara canis expand in vitro human $\mathrm{T}$ cells with stabel and opposite (type $1 \mathrm{~T}$ helper or type $2 \mathrm{~T}$ helper) profile of cytokine production. J. Clin. Invest. 88: $346-350$.

13. Derynck, R. and Choy, L. 1997. Transforming growth factor- $\beta$ and its receptors. pp. 593-636. In: The Cytokine Handbook, 3rd ed. (Thomson, A. ed.), Academic Press, San Diego.

14. Gröne, A., Frisk, A. L. and Baumgartner, W. 1998. Cytokine mRNA expression in whole blood samples from dogs with natural canine distemper virus infection. Vet. Immunol. Immunopathol. 65: 11-27.

15. Gröne, A., Weckmann, M. T., Capen, C. C. and Rosol, T. J. 1996. Canine glyceraldehyde-3-phosphate dehydrogenase (GAPDH) complementary DNA: Polymerase chain reaction amplification, cloning, partial sequence analysis, and use as loading control in ribonucleases protection assays. Am. J. Vet. Res. 57: 254-257.

16. Guo, J., Rapoport, B. and McLachlan, S. M. 1999. Balance of Th1/Th2 cytokines in thyroid autoantibody synthesis in vitro. Autoimmunity 30: 1-9.

17. Kehrl, J. H. 1991. Transforming growth factor- $\beta$ : an important mediator of immunoregulation. Int. J. Cell Cloning 9: 438450 .

18. Kekow, J., Wachsman, W., McCutchan, J. A., Gross, W. L., Zachariah, M., Carson, D. A. and Lotz, M. 1991. Transforming growth factor-beta and suppression of humoral immune responses in HIV infection. J. Clin. Invest. 87: 1010-1016.

19. Kim, S. J., Kehrl, J. H., Burton, J., Tendler, C. L., Jeang, K. T., Danielpour, D., Thevenin, C., Kim, K. Y., Sporn, M. B. and Roberts, A. B. 1990. Transactivation of the transforming 
growth factor beta 1 (TGF-beta 1) gene by human T lymphotropic virus type 1 tax: a potential mechanism for the increased production of TGF-beta 1 in adult T cell leukemia. J. Exp. Med. 172: 121-129.

20. Krawiec, D. R. and Gaafar, S. M. 1980. Studies of the immunology of canine demodicosis. J. Am. Anim. Hosp. Assoc. 16: 669-676.

21. Lemarie, S. L. and Horohov, D. W. 1996. Evaluation of interleukin-2 and interleukin-2 receptor expression in dogs with demodicosis. Vet. Dermatol. 7: 213-219.

22. Lopatin, U., Yao, X., Williams, R. K., Bleesing, J. J. H., Dale, J. K., Wong, D., Teruya-Feldstein, J., Fritz, S., Morrow, M. R., Fuss, M., Sneller, M. C., Raffeld, M., Fleisher, T. A., Puck, J. M., Strober, W., Jaffe, E. S. and Straus, S. E. 2001. Increases in circulation and lymphoid tissue interleukin-10 in autoimmune lymphoproliferative syndrome are associated with disease expression. Blood 97: 3161-3170.

23. Olivery, T., Dean, G, A., Tompkins, M. B., Dow, J. L. and Moore, P. F. 1999. Toward a canine model of atopic dermatitis: amplification of cytokine-gene transcripts in the skin of atopic dogs. Exp. Dermatol. 8: 204-211.

24. Paludan, S. R. 1998. Interleukin-4 and interferon-gamma: the quintessence of a mutual antagonistic relationship. Scand. $J$. Immunol. 48: 459-468.

25. Paulik, S., Mojzisova, J., Bajova, V., Baranova, D. and Paulikova, I. 1996. lymphocyte blastogenesis to concanavalin A in dogs with localized demodicosis according to duration of clinical disease. Vet. Med. Czech 41: 245-249.
26. Prud'homme, G. J. and Piccirillo, C. A. 2000. The inhibitory effects of transforming growth factor-beta- 1 (TGF- $\beta 1$ ) in autoimmune diseases. J. Autoimmunity 14: 23-42.

27. Schorle, H., Holtschke, T., Hunig, T., Schimpl, A. and Horak, I. 1991. Development and function of T cells in mice rendered interleukin-2 deficient by gene targeting. Nature (Lond.) 352: 621-624.

28. Scott, D. W., Miller, W. H. and Griffin, C. E. 1995. Canine demodicosis. pp. 417-432. In: Small Animal Dermatology, 5th ed (Scott, D. W., Miller, W. H. and Griffin, C. E. eds.), W. B. Saunders, Philadelphia.

29. Sher, A. and Coffman, R. L. 1992. Regulation of immunity to parasites by T cells and T cell-derived cytokine. Annu. Rev. Immunol. 10: 385-409.

30. Stevens, T. N., Bossie, A., Sanders, V. M., Fernandez-Botran, R., Coffman, R. L., Mosmann, T. R. and Vitetta, E. S. 1988. Regulation of antibody isotype secretion by subsets of antigenspecific helper T cells. Nature (Lond.) 334: 255-258.

31. Tabata, T., Hazama, S., Yoshino, S. and Oka, M. 1999. Th2 subset dominance among peripheral blood $\mathrm{T}$ lymphocytes in patients with digestive cancers. Am. J. Surg. 177: 203-208.

32. Tani, K., Hayashiya, S. and Taura, Y. 2000. Oral ivermectin used to treat generalized canine demodicosis in 6 dogs. J. Jpn. Vet. Med. Assoc. 53: 71-74 (Abstract in English).

33. Zhang, M. and Tracey, K. J. 1997. Tumor necrosis factor. pp. 517-548. In: The Cytokine Handbook, 3rd ed. (Thomson, A. ed.), Academic Press, San Diego. 